\title{
Managing acute dental pain without codeine
}

\section{Leanne Teoh}

Dentist, Bundoora Dental

Clinic, Melbourne

Aust Prescr 2020;43:64

https://doi.org/10.18773/

austprescr.2020.013

Related article:

Management of dental

pain in primary care

Aust Prescr 2020:43:39-44
Opioids have a limited role in general dental practice. Non-steroidal anti-inflammatory drugs (NSAIDs) are superior to opioids for dental pain ${ }^{1,2}$ and are therefore recommended as first line in Therapeutic Guidelines: Oral and Dental. ${ }^{3}$ NSAIDs inhibit the prostaglandins responsible for the inflammatory mediators that drive the postoperative pain, swelling and hyperalgesia after procedures such as extractions.

Opioids only interrupt the nociceptive pathway to inhibit pain perception and do not target inflammation. Despite this, Australian dental opioid prescribing has increased in recent years. ${ }^{4} \mathrm{~A}$ recent survey showed that $16-27 \%$ of dentists would preferentially use an opioid or paracetamol instead of NSAIDs for pain relief. ${ }^{5}$

Codeine has limited efficacy for dental pain. A recent double-blind randomised-controlled trial investigated the effectiveness of adding codeine to standard analgesic doses of paracetamol and ibuprofen after surgical removal of impacted mandibular third molars. It reported that additional high-dose codeine (60mg) did not reduce pain scores compared to paracetamol and ibuprofen alone. ${ }^{6}$ In addition, a randomised, double-blind, placebo-controlled trial showed that combinations of varied doses of paracetamol with ibuprofen provided superior pain relief after impacted third molar surgical extractions, compared to paracetamol with codeine.? Patients who took codeine combination products also experienced more adverse effects compared with patients who received ibuprofen and paracetamol combinations.?

Codeine is a prodrug that is transformed by cytochrome P450 2D6 into morphine, resulting in the analgesic effect.' Approximately $6-10 \%$ of Caucasians and $1-2 \%$ of Asians have two non-functional alleles of this enzyme so codeine will not provide effective analgesia for these patients. ${ }^{8}$ In contrast, up to $10 \%$ of Caucasians, $1-2 \%$ of Asians and $21 \%$ of people from the Middle East are ultra-rapid metabolisers and can generate very high concentrations of morphine from codeine, which may lead to toxicity. ${ }^{8}$ In addition, due to pharmacogenomic variability, differences in metabolism and concerns about toxicity, codeine is contraindicated in children under 12 years old, those under 18 years old undergoing an adenoidectomy or tonsillectomy, and in breastfeeding women. There is also the risk of dependence.

Opioids are not first-line drugs for dental pain. As there are established superior alternatives, codeine and other opioids have limited use in general dental practice.

\section{Conflict of interest: none declared}

\section{REFERENCES}

1. Becker DE. Pain management: Part 1: Managing acute and postoperative dental pain. Anesth Prog 2010;57:67-79. https://doi.org/10.2344/0003-3006-57.2.67

2. Dionne RA, Gordon SM, Moore PA. Prescribing opioid analgesics for acute dental pain: time to change clinical practices in response to evidence and misperceptions. Compend Contin Educ Dent 2016;37:372-8;quiz379.

3. Oral and Dental Group. In: eTG complete [digital]. Melbourne: Therapeutic Guidelines Limited; 2019 www.tg.org.au [cited 2020 Mar 1]

4. Teoh L, Stewart K, Marino RJ, McCullough MJ. Current prescribing trends of dental non-antibacterial medicines in Australia from 2013 to 2016. Part 2. Aust Dent J 2018;63:338-46. https://doi.org/10.1111/adj.12613

5. Teoh L, Marino RJ, Stewart K, McCullough MJ. A survey of prescribing practices by general dentists in Australia. BMC Oral Health 2019;19:193. https://doi.org/10.1186/ s12903-019-0882-6

6. Best AD, De Silva RK, Thomson WM, Tong DC, Cameron CM, De Silva HL. Efficacy of codeine when added to paracetamol (acetaminophen) and ibuprofen for relief of postoperative pain after surgical removal of impacted third molars: A double-blinded randomized control trial. J Oral Maxillofac Surg 2017;75:2063-9. https://doi.org/ 10.1016/j.joms.2017.04.045

7. Daniels SE, Goulder MA, Aspley S, Reader S. A randomised, five-parallel-group, placebo-controlled trial comparing the efficacy and tolerability of analgesic combinations including a novel single-tablet combination of ibuprofen/paracetamol for postoperative dental pain. Pain 2011;152:632-42 https://doi.org/10.1016/j.pain.2010.12.012

8. Australian medicines handbook. Adelaide: Australian Medicines Handbook Pty Ltd; 2019. https://amhonline.amh.net.au [cited 2020 Mar 1] 